meter had become crusted with ice spicules, and it had to be thawed out before it could be used. Many other difficulties had to be encountered, and it is surprising that any successful observations were made; but Mr. Mossman, assisted by Mr. W. Martin, secured, besides other observations, hourly observations on twenty days.

The magnetic observations are discussed by Dr. Chree, F.R.S., who remarks that the results show how very carefully the observations were made. The observations extended over the period May, 1903, to February, 1904.

The following values are given:- declination, $5^{\circ} 3 \mathrm{I}^{\prime} \cdot 2$ east; inclination, $54^{\circ} 30^{\prime} \cdot 6$ south; horizontal force, 0.25704 ; mean daily range of declination obtained from the hourly readings, $8^{\prime} \cdot 65$.

While the Scotia was anchored and frozen in Scotia Bay observations of the tide were made by means of a very simple gauge. A long wire, fastened to the sea floor by a heavy weight, passed over a pulley, and was kept taut by a lighter weight at the other end. As the ship rose and fell with the tide this weight moved up and down a vertical scale, which was observed half-hourly.

The tides seem to be normal for a place in the Southern Ocean. The semi-diurnal tides are considerable, but the solar tide is unusually large compared with the lunar tide, the ratio being three-fifths, or 0.6 , as compared with 0.465 of the equilibrium theory. The semi-diurnal tides are almost exactly " inverted," so that low water occurs very nearly when the moon is on the meridian.

\section{THE METEORS OF HALLEY'S COMET.}

I $\mathrm{N}$ view of the approaching return of Halley's comet, the Aquarid meteor shower of May ought to be awaited with special interest. We know comparatively little of this system, as it has been seldom observed. It is certain, however, that it is the richest of our May showers, and that its radiant point conforms very nearly both in date and place with the radiant and epoch of particles following the path of Halley's comet. This circumstance alone is significant, and the supposed connection of the comet and meteoric display will be sure to receive ample investigation during the next few years.

The Aquarids should be looked for after I a.m. in the mornings between the end of April and May 7, and they are directed from a region at about $337^{\circ}-2^{\circ}$, just below the equator. Lieut.-Colonel Tupman determined the radiant as about $10^{\circ}$ west of the point assigned, and further observations are required to ascertain the exact place, and also the precise date of the maximum of the shower.

If really associated with Halley's comet, the meteors ought, in immediate ensuing years, greatly to increase in numbers, though we possess no historical records of rich showers having been observed in 1759 or 1835 , when the comet previously returned to perihelion. But many meteoric phenomena have eluded recognition, and it is very possible that some returns of these Spring Aquarids may have escaped notice, as they are only visible just before sunrise, and were never specially looked for until after their discovery nearly forty years ago by Lieut.-Colonel Tupman. This stream, like the Perseids and Leonids and many other showers, is evidently one visible nearly every year, and forming a complete ellipse. It now remains for observations in immediately ensuing years to determine whether, like the Leonids and Andromedids of November, it develops unusual intensity near the time of return of the parent comet.

W. F. DenNing.

\section{SOME UNSOLVED PROBLEMS IN METAL $M I N I N G .^{1}$}

IN one sense every mine is an unsolved problem from the day the first pick is put into the ground until the mine is finally abandoned as exhausted, and even then it is not always certain that it really is worked out, and that sinking or driving another to feet might not give it a renewed lease of life. Unlike most engineering problems, which have generally to be solved before work is com-

1 From the "James Forrest" Lecture, delivered at the Institution of Civil Engineers on April 27 by Prof. Henry Louis.

NO. 2009, VOL. 77] menced, a mining problem is never fully solved until all work upon it is finally concluded.

At the very outset, even before we are in a position to attack the different subdivisions of the subject, we are brought face to face with what may almost be described as one of the fundamental problems underlying the whole of metal-mining, and one the solution of which can never attain finality. The work of the metal-miner being limited to the extraction from the earth's crust of the ores of the various metals, whilst it is the business of the metallurgist to smelt these, so as to reduce therefrom the metals that they contain, and to fit the latter for their use in the arts, the question what constitutes an ore is one that the miner cannot answer for himself, and for the reply to which he is dependent entirely upon the development of metallurgical science for the time being. Not all metalliferous minerals are ores from the smelter's point of view. Take, for example, an ordinary brick clay, which is a complex hydrous silicate containing, say, is per cent. of aluminium and 5 per cent. of iron; it is true that we can extract both these metals from it by a series of complicated laboratory processes, but no means for doing this economically on a practical working scale have yet been discovered. Hence no one would dream of calling clay an ore of aluminium, and far less of iron. Nevertheless, it is not beyond the bounds of possibility that our modern metallurgists, or their younger and more progressive brethren, the electro-metallurgists, may within a few years devise some practicable process for extracting aluminium from clay, when clay would straightway become an ore of aluminium, though it is not one now; and if perchance it happened that comparatively pure oxide of iron were obtained as a by-product in the same process, the clay might even be reckoned as an ore of iron also. Until some such process shall be devised, clay is looked upon by the metal-miner as a non-metallic mineral, as so much worthless gangue or waste. The history of metal-mining has shown again and again that the waste rock of one generation is the valuable ore of another, as, for example, the zinc blende of the Alston district, which is now being recovered from the waste which the old miners had left behind as worthless in their excavations, or had thrown aside on their waste heaps, the value of the mineral having been recognised when a Belgian metallurgist discovered how to extract zinc from it.

The point may be further illustrated by a consideration of the world's supply of iron ore; iron, the most useful of all metals, is at the same time, next to aluminium, the most abundant, geologists calculating that 4.7 per cent. of the earth's crust consists of iron: if this estimate be correct, the very small portion of the earth's crust underlying the London Metropolitan area (fifteen miles' radius) down to the depth of only one mile would contain no less than 360,000 millions of tons of iron, none of which is in the form of a true iron ore. At the present day no one would call a mineral containing less than 25 per cent. of iron an iron ore, and unless it contains double that percentage it will not find a very ready or a very appreciative market amongst iron smelters.

As the result of various improvements in the last few decades, the whole trend of modern mining is towards the utilisation of large deposits of low-grade material, the increased scale of operations enabling economies to be effected that were impossible whilst small quantities alone were dealt with. One of the cardinal problems that will confront our successors will be how to work with profit minerals of lower grade than any that we have yet attacked, so as to enable the miner to include within his sphere of operations deposits too poor for us to deal with to-day.

The possibility of determining by some means the whereabouts of the hidden treasures of the earth has long been an object of the miner's desire, the methods for accomplishing which range from the mediæval adept with his divining rod, belief in which is not wholly extinct to-day, down to a series of modern attempts to use electric currents for the same purpose. Up to the present these attempts have been unsuccessful, in spite of the ambitious claims of some of their advocates.

In view of the fact that minerals differ so widely in their electric and magnetic properties, it is quite possible 